\title{
Paroxysmal exertion-induced dyskinesia
}

INSERM

\section{Source}

INSERM. (1999). Orphanet: an online rare disease and orphan drug data base.

Paroxysmal exertion-induced dyskinesia. ORPHA:98811

Paroxysmal exertion-induced dyskinesia (PED) is a form of paroxysmal dyskinesia (see this term), characterized by painless attacks of dystonia of the extremities triggered by prolonged physical activities. 